\title{
Vegetarianism and Human Health
}

Usha R. Palaniswamy

\begin{abstract}
Summary. Vegetarianism dates back to a time before recorded history and, as many anthropologists believe, most early humans ate primarily plant foods, being more gatherers than hunters. Human diets may be adopted for a variety of reasons, including political, esthetic, moral, environmental and economic concerns, religious beliefs, and a desire to consume a more healthy diet. A major factor influencing the vegetarianism movement in the present time is primarily associated with better health. Epidemiologic data support the association between high intake of vegetables and fruit and low risk of chronic diseases and provide evidence to the profound and long-term health benefits of a primarily vegetarian diet. Vegetables and fruit are rich sources of nutrients, vitamins, minerals, and dietary fiber as well as biologically active nonnutrient compounds that have a complementary and often multiple mechanisms of actions, including antioxidant, anti-inflammatory, hypoglycemic, hypocholesterolemic, and hypolipidemic properties, and mechanisms that stimulate the human immune system. Because of the critical link established between diet and health, consumers have begun to view food as a means of self-care for health promotion and disease prevention. Functional foods are targeted to address specific health concerns, such as high cholesterol or high blood sugar levels, to obtain a desired health benefit. Functional properties identified in a number of plant species have led to a modern day renaissance for the vegetarian movement.
\end{abstract}

I $\mathrm{t}$ is often asserted that humans are naturally vegetarian because the human body resembles plant eaters, not carnivores. However, humans are omnivores, capable of eating either meat or plant foods, or general feeders, with more generalized anatomical and physiological traits. Human beings have developed feeding habits that is individualized, and acquired through a number of factors including religious and philosophical beliefs, habitat, availability, taste preferences, socioeconomic status, and specific health requirements.

Recently, a number of epidemiological and clinical trials have established a strong link between the intake of fruit and vegetables and a lower risk of several chronic diseases and conditions including cancer and heart disease (Hankey and Leslie, 2001; Key et al., 2002, Lampe, 1999). Additionally, scientific advances have aided in a greater understanding of the potential advantages of a vegetarian diet and the role of fruit and vegetables in human health promotion and disease prevention. The suggested benefits of a predominantly vegetarian diet are so many that Americans, who were meat and potato dieters and finding self-definition in steaks, pot-roasts, hot dogs, and hamburgers just a decade ago, have paused to reconsider their food choices. In the United States until recently, vegetarians were scarce and considered as being odd, intimidating, cranky, fussy, and moralistic. Today, the vegetarian choices have become mainstream and continue to grow in popularity. At present many mainstream restaurants now feature vegetarian dishes regularly (Restaurants USA, 1999).

$\overline{\text { School of Allied Health-Asian American Studies Institute, U-2101 University of Connecticut, Storrs, CT } 06269 .}$ 
The term vegetarianism generally refers to a diet that is free from meat on the basis of religious, spiritual, ethical, economic, hygiene, and environmental considerations or the simple desire for better health, free from chronic diseases and conditions. There exists varying degrees of vegetarianism, depending on what a vegetarian includes in the diet besides products of plant origin: the vegans are pure vegetarians and do not include any animal product in their diet; the lacto-ovo vegetarians include dairy and eggs in their diet; the lacto-vegetarians consume dairy, but not eggs; the ovo-vegetarians consume eggs, but not milk; the pesco vegetarians eat fish, but no other meat; the pollo vegetarians eat poultry, but no other meat; the macrobiotics eat relatively high amounts of brown rice, accompanied by smaller amounts of fruit, vegetables and pulses; the fruitarians eat only vegetables and nuts; the raw-foodists and natural hygienists do not consume any processed foods and adhere to a very strict vegetarian diet; sproutarians who eat a diet primarily around sprouted seeds such as bean sprouts (Vigna radiata), wheat sprouts (Triticumsp.) or broccoli sprouts (Brassica oleraceae var. italica); and the term partial vegetarian (or part-time vegetarian) can be applied to any of the above definitions used for individuals who occasionally consume some type of meat product due to personal, cultural, or traditional reasons. In an online survey by Time/CNN, consisting of 10,007 adult Americans, 57\% reported to be semi-vegetarians, 36\% ovo-lactovegetarians, $5 \%$ vegans and $2 \%$ other types ofvegetarians (HarrisInteractive, 2002). Since the simple term vegetarian or vegetarian diet does not provide for all these minor variations, several other terms including plant-based diet or living food have been suggested for use to describe a diet that is predominantly based on foods derived from plants (Dwyer, 1999; Weinsier, 2000). More recently, it has also been suggested that children raised on hit movies like Babe and Chicken Run tend to nonviolent diets as a way to save their movie heroes (Corliss, 2002).

\section{History of vegetariansim}

Abstention from eating meat because it is wrong to kill animals has been held by a number of ancient philosophers, including Zoroaster, Buddha, Mahavira, and Emperor Ashoka in the East, and Pythogoras, Plutarch, Plotinus,
Porphyry and Plato in the West. In the East, the antiquity of vegetarianism can be traced back to Zoroaster [628-55] BCE (before current era)], the founder of Zoroastrianism or Parseeism in India, Buddha (566-486 BCE) the founder of Buddhism, Mahavira (599-527 BCE) the founder of Jainism, and Ashoka (265-238 BCE) the great emperor of India (Spencer, 1995). Although Hindhuism does not require a strict vegetarian diet, it encourages a satvic (one of the three characteristics of things in the universe, which is pure, creative, illuminating and healthy) vegetarian diet for good health, as befitting for gods and sages, and strictly forbids killing of the cows. A vegetarian diet is advocated in Indian traditional medicine, Ayurveda, which is often defined as a way of life (rather than a medical system), for a healthy and long life. Vegetarianism is encouraged in the ancient verses of the Upanishads and also mentioned in Rig Veda, the most sacred of ancient Hindu texts. Pivotal to such religions are doctrines of nonviolence and respect for all life forms. Thus, vegetarianism in the East was tied to philosophical and religious beliefs and faiths as well as better health and longer life.

The Eastern philosophers had a considerable influence in the West when Pythagoras (580-500 BCE) was influenced by the teachings of Zoroaster, Buddha, and Mahavira. Pythagoras was a prominent vegetarian and the Pythogorean diet came to mean avoidance of the flesh of slaughtered animals (Spencer, 1995). Pythagorean philosophical morality was not to kill living creatures, never to eat meat and to abstain from animal sacrifice, because all animate are akin. Plutarch [46-120 CE (current era)] connected vegetarianism with preservation of health: "indigestion is to be feared after flesh-eating for it very soon clogs us and leaves ill consequences behind it. It would be best to accustom oneself to eat no flesh at all.... and from over-eating man derives most of his diseases" (Plutarch, 1889).

In the $17^{\text {th }}$ century, medical as well as moral constraints were central to a vegetarian philosophy. Meat was considered a harmful food that could "breed great store of noxious humors," and that "flesh eating produced much sickness and a vice as well" (Ryder, 1979; Tryon, 1683). In the $18^{\text {th }}$ and $19^{\text {th }}$ century, the regard for animal life and welfare were intensified by the politically influential religious movement of
Evangelicalism. Oswald published The Cry of Nature (1791) expressing his outrage against cruel killings of animals (Whorton, 2001). In 1822, a law was passed to protect work animals from abuse (Turner, 1980).

In the West, the nutritional superiority of vegetarianism over an omnivorous diet was first demonstrated by George Cheyne, a physician and health writer who had personally benefited from turning a vegetarian. He was greatly convinced that flesh food "inflames the passions, and shortens life, begets chronical distempers and a decrepid age" (Cheyne, 1813). He recommendedvegetarianism exclusively for the physical well-being based on his clinical cases and personal benefits. William Lambe, another English physician who claimed benefits from turning to a vegetarian diet, insisted that a strict vegetarian diet was an absolute necessity to management of chronic illnesses. He proposed that meat was unnecessary and what is unnecessary cannot be natural and what is not natural cannot be useful to the human body (Lambe, 1815). Vegetarianism was brought to the United States by William Metcalfe, an envoy of Bible Christian Church, founded by William Cowherd, the first organization in the West requiring vegetarianism for membership (Spencer, 1995). In 1830, MetCalfe's movement involved Sylvester Graham, a Presbyterian minister who initiated a health reform based on the principle that "physiology must be congruent with morality", and "any behavior that tarnished the soul must also injure the body." He also advocated against alcohol, extramarital sex, latenight entertainments, and consumption of meat. During that period, William Beaumont, demonstrated that vegetarian diets needed more time and probably "greater powers of the gastric organs" than animal foods. Graham postulated, however that meat was more pathologically stimulating than vegetables. The present day graham crackers bear his name.

Vegetarians were also described as smelling better and of superior mental and physical strength and performance compared with meat eaters (Alcott, 1844). The first vegetarian society was formed in 1847, in England and the term vegetarian was first coined from the Latin vegetus that means lively or vigorous. In 1888, W.O. Atwater, who was the first director of U.S. Department of Agriculture (USDA) and the 
father of modern American nutrition, tabulated and published the fat, protein, and carbohydrate contents of various foods.

In early 1900s, John Harvey Kellog, a Seventh-Day Adventist who followed Graham's rules of health supported the autointoxication theory that proposed the intestinal autointoxication occurred through bacterial purification of undigested protein in the colon (Spencer, 1995). He believed in the significant contribution of fiber to the nutritional value of the vegetarian diet and proposed that modern people consumed a diet insufficient in roughage to stimulate the bowels to action. He claimed that the vegetarian diet was high in fiber, but low in protein and hence caused low autointoxication of the intestine and body.

In 1911, Casimir Funk discovered vitamin $B_{1}$ and coined the term vitamin in 1916. The American Dietetic Association was founded in 1917 in Cleveland, Ohio to promote sound nutrition information for the public, promoting optimal nutrition and well being for all people. In 1923, Elmer McCollum, a biochemist and nutritionist who discovered vitamins $A$ and $B$ estimated that at least $90 \%$ of the food eaten by most American families was restricted to white bread and butter, meat, potatoes, sugar and coffee and expressed concern over the general health and well being of Americans. He called for a national reform to educate and convert the public to replace the traditional diets to what he called the protective foods. The public attention was drawn to the increased intake of vitamins and fiber and resulted in the manufacture of breakfast cereal foods by Kelloggs and Charles W. Post. In the 1920s, the food processing industry became the largest manufacturing industry and the large food manufacturers like General Mills and Sunkist emerged and used the vitamin content of their products as a strong selling point (Dyson, 2000).

The Zen macrobiotic diet was developed in the 1930s by George Ohsawa, a Japanese philosopher who integrated traditional Asian medicine and belief with Western medicine and the Christian teachings. The Zen macrobiotic diet, which is based on the concept of yin and yang, (the two opposite forces of life), became popular in the 1960s. According to the philosophy behind Zen macrobiotics, disease results from an imbalance of yin and yang, which can be restored by an ideal dietary regimen that comprised of 10 stages, the last stage of which consisted of brown rice, salt and fluids that included mostly herbal teas. Reports indicate that such extreme vegetarianism resulted in many nutritional deficiencies and death in some cases and caused the decline of this dietary regimen after Ohsawa's death. Laterin 1978, Michio Kushi, who was inspired by Ohsawa's concept of integrating the Asian beliefs and Western medicine, founded the Kushi Institute in Becket, Mass. and developed several dietary regimens for various diseases, which were predominantly vegetarian, butincluded fish occasionally (Kushi and Kushi, 1992).

In the 1970s, Robert Atkins, a medical doctor, proposed the Atkins diet which advocates a high protein, high fat diet with a significant restriction of dietary carbohydrate (Atkins and Buff, 2000). The Atkins diet comprises of 50 to $75 \%$ of proteins and fats (meat, poultry, eggs, fish, seafood, cheese, nuts, seeds, olive (Olea europaea), avocado (Persea americana), fats and oils), 25 to $50 \%$ of complex carbohydrates (vegetables, grains, whole-grain flour products, and legumes), and less than $10 \%$ of simple carbohydrates (fruit, fruit juice, sweets, milk, yogurt). The Atkins diet advocates a crucial balance between two

Table 1. Historical overview of food guides and food choices for Americans: the most up-to-date advice from nutrition scientists that formed the basis of Federal nutrition policy in 1943, 1958, and 1989 for a healthful diet (U.S. Department of Agriculture, 1943, 1958, 1989).

\section{Food group pattern}

Basic Seven (1943)

1. Green and yellow vegetables,

2. Citrus fruit, tomatoes, raw cabbage,

3. Potatoes, other vegetables, fruits

4. Milk and milk products

5. Meat, poultry, fish, eggs, dried legumes

6. Bread, flour and cereals

7. Butter and fortified margarine

\section{Basic Four (1958)}

1. Milk

2. Meat

3. Vegetable and fruits

4. Bread and cereal

Six-food groups (1989)

1. Bread, cereal, other grains

2. Fruits

3. Vegetables

4. Meat, poultry, fish,

5. Milk, cheese, yogurt

6. Fats, sweets, alcoholic beverages pillars in the choice of carbohydrates: eating high-quality complex carbohydrates and high in the anti oxidants [e.g., carrots (Daucus carota), beets (Beta vulgaris), peas (Pisum sativum), and green leafy vegetables such as spinach (Spinacea oleracea)]. Atkins proposed that by limiting carbohydrate intake the body burns stored fat. Since high-protein, high-fat, low-carbohydrate diets force the body into a fasting state called ketosis, which may bring about quick weight loss. The Atkins diet has became very popular among people who are obese because it guaranteed significant weight loss. Numerous health agencies, however, including the American Institute for Cancer Research (AICR), have expressed concern over the choice of this dietary regimen because ketosis can lead to muscle breakdown, dehydration, headaches, nausea, and kidney problems.

Since the 1940s, federal agencies began translating the new knowledge gained from research into practical dietary guidelines for consumers. The seven-group plan was developed by USDA in 1943, which was then revised to the basic four in 1958, and later the six-food group pattern in 1989 (Table 1). Beginning in 1980, there has been an overwhelming emphasis on diet and drates that are low in simple carbohy- 
health both in the areas of nutrition research and its applications to American food habits. The importance of diet for overall health promotion and disease prevention had been brought to the attention of the public by the government, food industry, innumerable professional and consumer groups, and the mass media. In 1984, the food guide was first presented as a wheel by the American Red Cross-USDA nutrition course, then as a table, and later in 1992, in the form oflogos in a pyramid (American Dietetic Association, 1992; Bonci, 2001). The food pyramid is a graphic representation that demonstrates the relative importance of food groups providing minimal daily servings. The pyramid was established with three key themes: variety, proportionality, and moderation. Variety is shown through the separate food group selection and food group names, proportionality by the size of food group sections and numbers of servings for each group, and moderation by the relative sizes of portions as parts of the pyramid, small size at the top and accompanying text (e.g., use sparingly for fat and sugar group of foods). Food pyramid for various groups of vegetarians (Fig. 1) has been developed (Haddad et al., 1999).

Since its formulation, the pyramid has been modified to suit many subgroups including the minority and ethnic populations, infants, vegetarians, and other special groups (e.g., soul food pyramid, soy foods pyramid), written in native languages for the ethnic groups and non-English speaking immigrants, and the food items chosen to reflect familiar ethnic foods and also modified as a pagoda for the Chinese (Chinese Nutrition Society, 2000). A major concern in establishing the actual number of servings is the differential nutritional composition of fruit and vegetables due to the genetic variability and/or other external and environmental conditions, processing and handling (Davis et al., 2001).

\section{Health benefits of vegetarian diets}

A survey in the early 1990s (Vegetarian Times, 1992) reported that more people reported that their choice of a vegetarian diet is for health reasons $(46 \%)$ than for animal rights ( $15 \%)$, family or friend influence $(12 \%)$, ethics (5\%), environmental issues $(4 \%)$, and other reasons $(18 \%)$. There is accumulating epidemiological, laboratory and clinical evidence that high consumption of fruit and vegetables protects against degenerative diseases including cancers, ischemic heart disease (Kwok et al., 2000; Steinmetz and Potter, 1991), and that vegetarians have a lower risk of morbidity and mortality form several degenerative diseases than do nonvegetarians (Key et al., 1996; Knutsen, 1994). Veg-

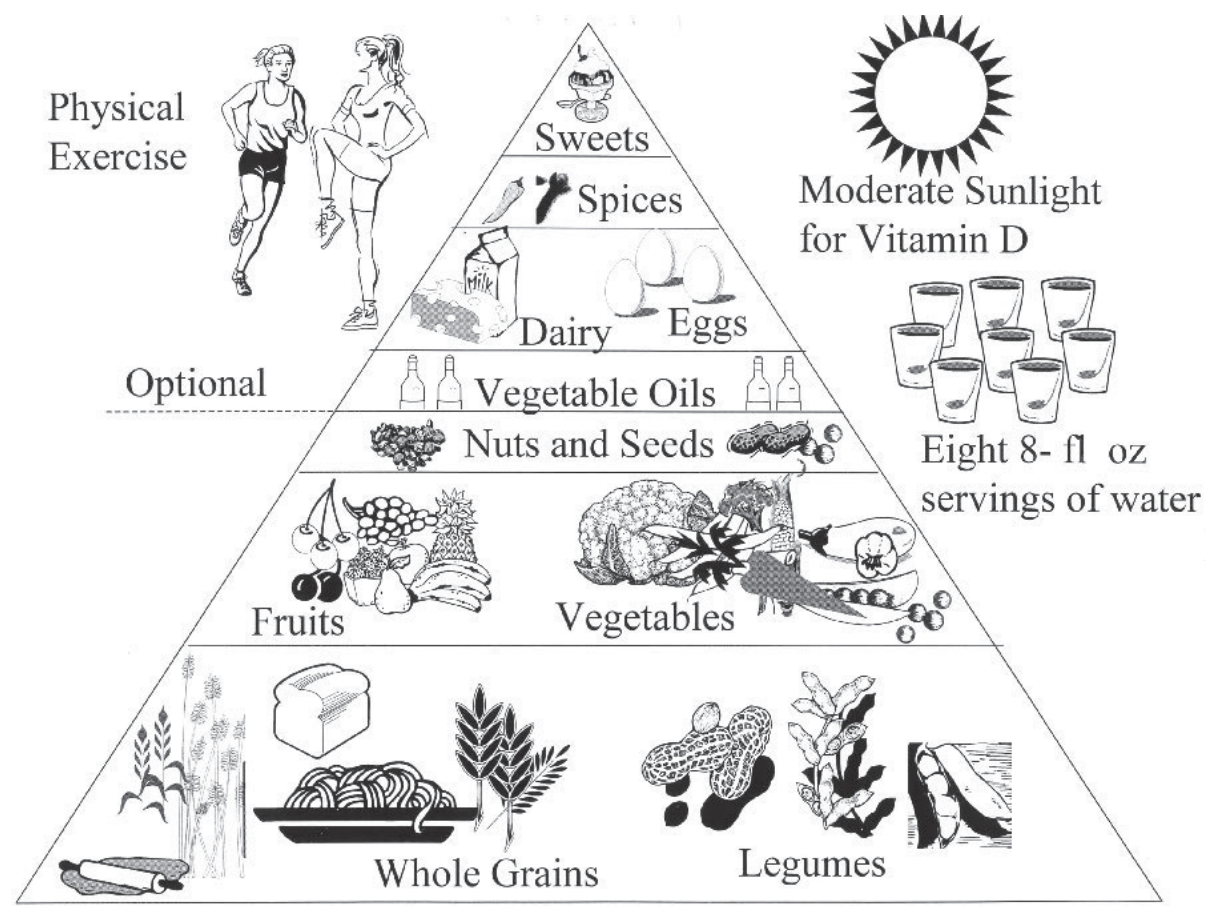

Fig. 1. Vegetarian food guide pyramid. Design of the pyramid based on the suggested model, Haddad et al. (1999); $8 \mathrm{fl} . \mathrm{oz}=237 \mathrm{~mL}$. etarian diets are also reported to reverse coronary artery disease (Franklin et al., 1995; Gould et al., 1995); vascular dilatory responses of lacto-ovo-vegetarians were better and may help to account for the lower incidence of atherosclerosis and cardiovascular mortality (Lin et al., 2001). Vegetarians may be at lower risk of dying from diabetes than nonvegetarians (Snowdon and Phillips, 1985), because the plant foods high in fiber and low in glycemic index offer benefits in prevention and in the clinical management of diabetes, reducing the incidence of diabetes by $40 \%$ (Salmeron et al., 1997). The high fiber content of legumes, fruit, and vegetables also increase fecal bulk and decrease transit time, thus reducing the exposure of the intestinal epithelium to mutagens (McIntyre et al., 1993).

Several of the phytochemicals such as flavonoids, isothiocyanates, and allyl sulfides derived from fruit and vegetables are inhibitors of carcinogenesis, modulating the enzyme system responsible for metabolizing carcinogens, which can decrease the incidence of cancers (Lampe, 1999; Messina, 1999). Vegetarians are also reported to have higher antioxidant vitamin levels in the blood serum (Hanninen etal., 2000; Pronczuk et al., 1992). Vegetarian diets were beneficial to bone health (Anderson, 1999) as well as in improving age-related neurological dysfunctions and brain performance (Kuresh and Joseph, 2001). It has been proposed that since the vegetarians consume many carbohydraterich plant foods such as fruit and vegetables, cereals, pulses, and nuts, their diet contains more antioxidant vitamins (vitamin $\mathrm{C}$, vitamin $\mathrm{E}$, and beta-carotene), phytic acid, and polyphenols that inhibit formation of $\mathrm{N}$-nitroso compounds (potential carcinogens) (Bartsch and Frank, 1996, Rauma and Mykkänen 2000). Lignins and phytoestrogens in soy have been shown to lower the risk of hormone-dependent cancers (Phipps, et al., 1993). Certain oligosaccharides have growth-promoting effects on bifidobacteria that are important for the health of the colon, maintaining a healthy colon and decreasing the risk of colon cancer (Mitsuoka, 1982).

The early model on the adequacy of vegetarian diets and public health risks and benefits (Fig. 2), which prevailed for the first part of the $20^{\text {th }}$ century, illustrated that if a population followed a vegetarian diet, that population would be more prone to develop nutri- 


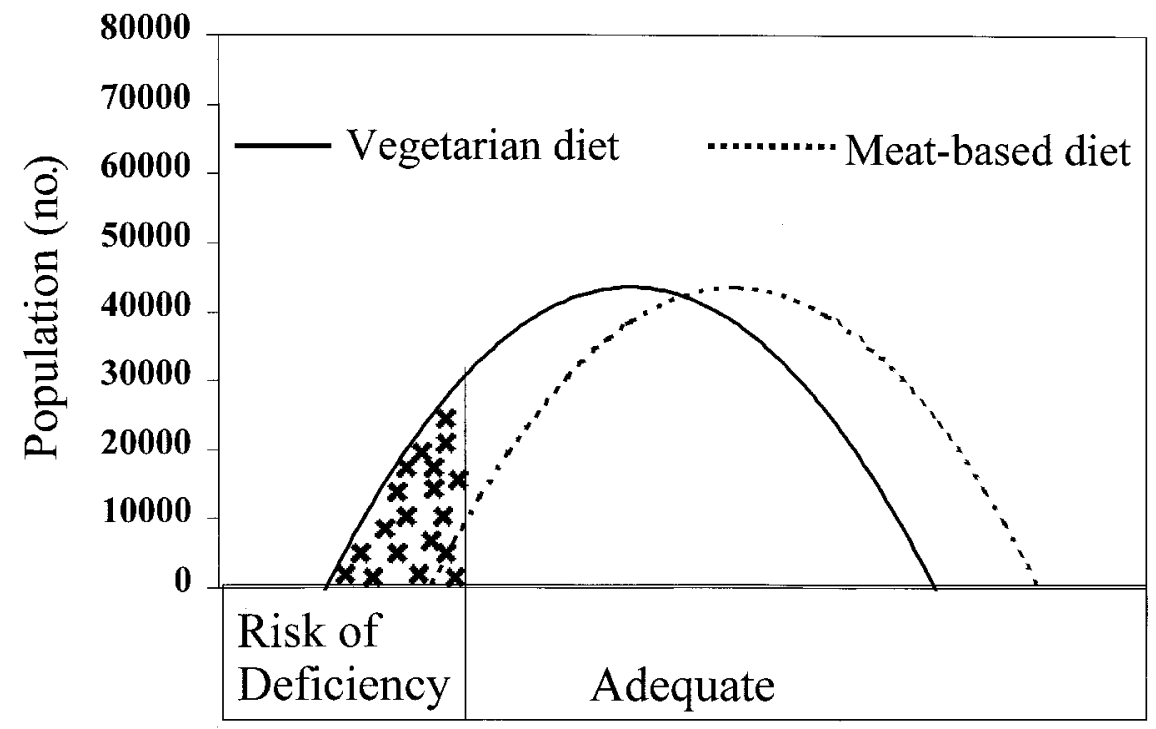

\section{Health Status}

Fig. 2. Early model on the adequacy of vegetarian diets. The area under the curve public health represents the proportion of individuals in a population for whom a given diet may be adequate or deficient (Sabaté, 2001).

ent deficiency diseases than those that followed a diet based on animal foods (Sabaté, 2001). This model was rightly termed the model on the adequacy of vegetarian diets because it was based on the available knowledge at a time of numerous nutrient deficiencies being recorded in clinical trials on vegetarians. This early model only considered the health risks posed on the vegetarians and suggested that populations include meat and dairy products to decrease the nutrient deficiencies and did not take into account the potential benefits of vegetarian diets. This is largely because during that period of time, the focus of research in human nutrition was on identifying and proposing nutrient intake for vegetarians and nonvegetarians who were mostly studied to determine if they met the recommended dietary allowances (RDA) for the various nutrients. The relationship between vegetarian diets and chronic illnesses and the long-term effect of diet on human health promotion and diseases were yet to be determined by nutritional epidemiology, which is a relatively new discipline.

The current model (Fig. 3), termed the model on the public health risks and benefits of vegetarian and meat-based diets, indicates the health risks and benefits of vegetarian and meat based diets (Sabaté, 2001). The area under each curve represents the proportion of the population for which a given diet pattern may be risky or beneficial to optimal health. In this model, the risk of disease with either a deficiency or an excess of nutrients are shown at both extremes and the area in the center represents the proportion of subjects for which the diet is optimal or most beneficial. As per this model, there is no overall difference in the risk-benefit ratio (proportion of subjects at risk divided by the proportion of subjects benefiting) of a

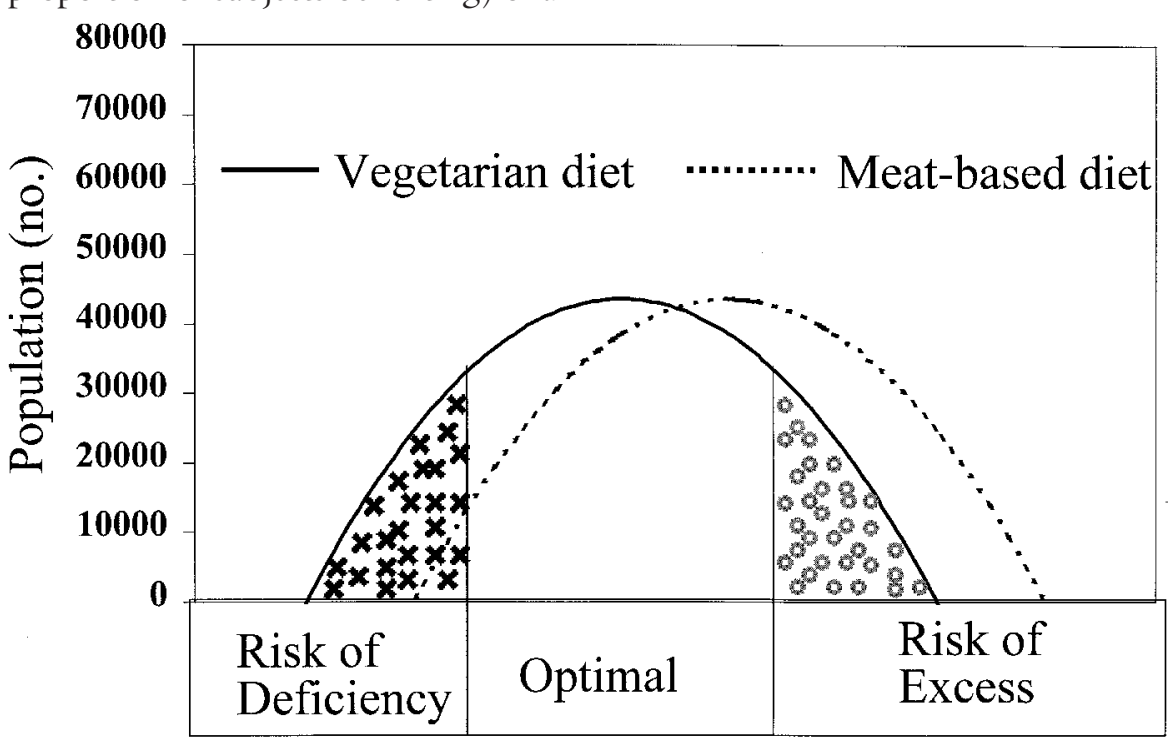

\section{Health Status}

Fig. 3. Current model on the public health risks and benefits of vegetarian and meat-based diets. The area under each curve represents the proportion of individuals in a population for whom a give diet pattern may be a health risk or benefit (optimal). At both extremes of the health continuum there is risk of disease through deficiency or excess of nutrients. The area in the center represents the proportion of individuals for whom the diet is optimal or most beneficial (Sabaté, 2001). 


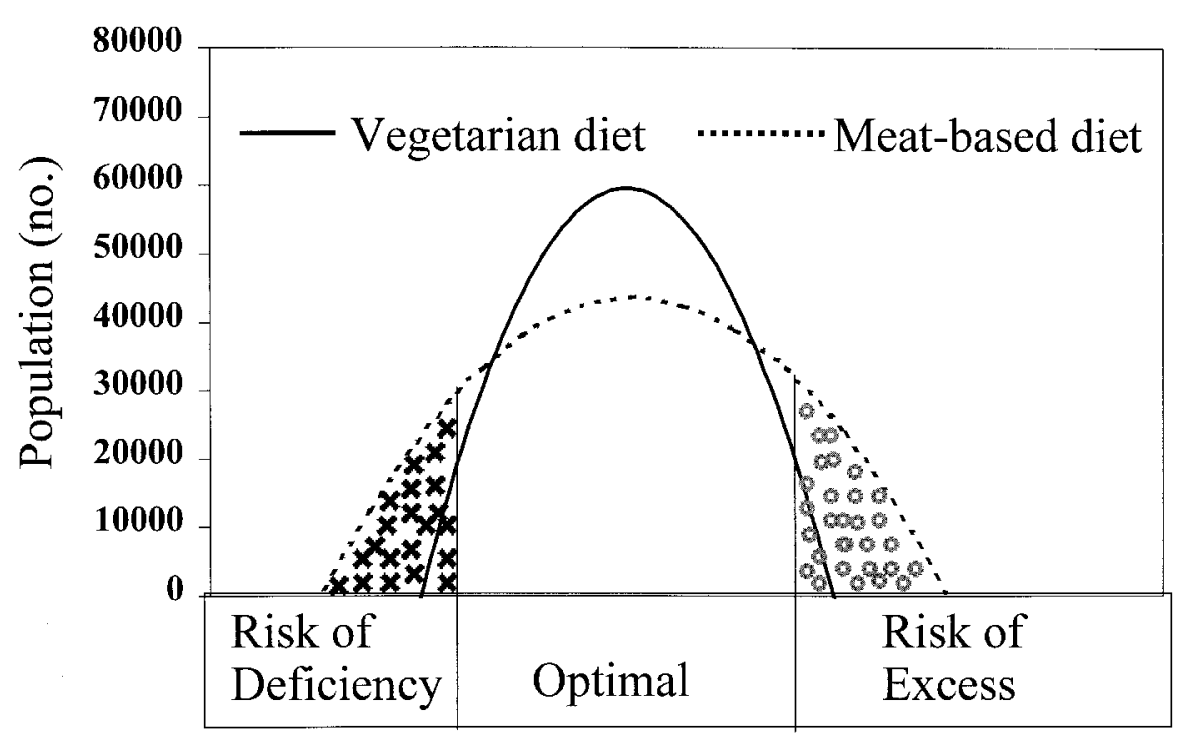

\section{Health Status}

Fig. 4. Proposed model on the public health risks and benefits of vegetarian and meat-based diets. The area under each curve represents the proportion of individuals in a population for whom a give diet pattern may be a health risk or benefit (optimal). At both extremes of the health continuum there is risk of disease through deficiency or excess of nutrients. The area in the center represents the proportion of individuals for whom the diet is optimal or most beneficial (Sabaté, 2001).

the population by health status. In this new model, the more favorable riskbenefit ratio for the vegetarian diet is clearly observed. The expanded area under the risk of deficiency under the meat-based diet curve indicates the risk of diseases due to phytochemical deficiency due to marginal intake of plant foods.

\section{Vegetarian diets and human dietetics}

While research supports the huge health benefits of largely plant-based diets, there are expressed concerns over the complete avoidance of animal meat and dairy in the daily diet. There exists great controversy over the superiority of predominantly vegetarian diets over nonvegetarian meat based diets (Whorton, 2001). Total vegetarians are likely to suffer from inadequate protein, calories, calcium, riboflavin, and zinc (Dwyer, 1991; Freeland-Graves, 1988). Vegetarian diets are deficient in $\mathrm{B}_{12}$ and hence vegetarians are also at risk of hyperhomocysteinemia, which can lead to vascular disease (Clarke et al., 1991).

Vegetarian dietary patterns present particular challenges to women because of their varying nutrient needs due to pregnancy and lactation across their life cycle. Additionally, the nutrient density in women's diet has to be greater than men, because they need fewer calories and their need for specific nutrients such as calcium, folic acid and iron are higher than men. Animal foods are high in calories, saturated fats and sodium and completely devoid of fiber and complex carbohydrates, and phytochemicals and thus do not promote optimal health and are harmful to health; however, animal foods are also good sources of protein, iron, calcium, iron, zinc, vitamin $\mathrm{B}_{6}$, and unique sources of vitamin $B_{12}$, preformed vitamin $A$, and vitamin $D$. If a woman eliminated animal foods completely, she must get these nutrients from other sources or nutrientsupplements to maintain normal health. Infants and children may suffer from extreme vegetarian diets resulting in poor growth and development (Kerr, 1974).

Vegetarian infants and children are smaller and grow at a slower rate as compared with the general meat eating populations (Erhard, 1973) and are more susceptible to tooth decay (Navia, 1979). Although dietary fat taken in the form of animal meat, eggs, and milk have been implicated in the development of chronic diseases, in many research reports, there is inconclusive evidence on the harmful effect of saturated and monounsaturated fats (Taubes, 2001). The benefits of polyunsaturated fats consumed in large amounts is ques- tioned because of the essential role played by the various groups of fats in human metabolism and membrane function (Lyon, 1977). It is also evident that humans require different types of fats for different purposes, both structural and functional (Abrams, 2001).

The American Dietetic Association's position on vegetarian diets is that when appropriately planned, "vegetarian diets are healthful, are nutritionally adequate, and provide health benefits in the prevention and treatment of certain diseases" (Messina and Burke, 1997). Some nutritional concerns expressed over a vegetarian diet include the inadequate intake and/or bioavailability of zinc and other trace elements (Rauma and Mykkänen 2000), calories, proteins, calcium, iron, riboflavin, and niacin as compared with the omnivores (Meirelles et al., 2001). It is generally believed that the vegetarian diets may provide less protein than an omnivorous diet. But it may be adequate because an omnivorous diet may really be providing more protein than is really needed and perhaps more healthy because lower protein in the diet is associated with a lower risk of osteoporosis, since high protein intakes lead to greater excretion of calcium (Leslie and St Pierre, 1999).

The low calories and high fiber content of a vegetarian diet is also viewed as an advantage. Although the iron content of the vegetarian diets are low, research indicates bioavailability and absorption of iron is higher in the vegetarians than in the omnivorous diet which contain a higher concentration of iron, but which is not as well absorbed. Additionally, some studies report that the ferritin level of vegetarians and omnivorous subjects were not significantly different (Ball and Bartlett, 1999), and an appropriately planned well-balanced vegetarian diet may be compatible with an adequate iron status (Craig, 1994).

In general, a well planned vegetarian diet must consider the following: choose whole grains, legumes, vegetables, soy products, seeds and nuts that are high in protein and good sources of both essential and nonessential amino acids; include good sources of iron, such as dried beans (Phaseolusvulgaris), spinach, green leafy vegetables; enriched products and whole grains; include vitamin $B_{12}$ fortified breakfast cereals; fortified soy beverages; and vitamin supplements; ensure the intake of adequate vitamin $\mathrm{D}$, by remaining in the sunlight, 
using fortified milk, or vitamin supplements; include vegetable greens such as spinach, kale (Brassica oleracea var. acephala) and broccoli, legumes and soybean (Glycinemax) products as good sources of calcium from plants and grains, and nuts and legumes as sources of zinc (McBride, 1998).

\section{Conclusions}

In the past decade, there has been a steady increase in the number of people choosing a vegetarian diet. In 1994, the number of vegetarians in the US was estimated as 12.4 million, twice the number in 1986 (Rajaram and Sabaté, 2000). The number of studies reporting the benefits of vegetarian diets has also increased tremendously. There has been an increase in publication in biomedical journals of review articles and original contributions in vegetarian nutrition (Sabate et al., 1999). A recent survey (HarrisInteractive, 2002) of 10,007 adult Americans, reported that more people attributed their choice of a vegetarian diet for health reasons (32\%), than for chemicals and hormones in meat products $(15 \%)$, not liking the taste of meat $(13 \%)$, love of animals $(11 \%)$, animal rights $(10 \%)$ and religious reasons $(6 \%)$. The choice of the public to adopt a more healthful diet and life style based on published scientific evidence is also closely related to the steadily increasing health care costs.

An ideal diet is one that can promote optimal health and longevity. Throughout history, human societies have developed varieties of dietary patterns based on available food plants and animals. As the primitive agricultural economies changed with advances in scientific knowledge, industry and technology, food scarcity turned to abundance, and principal diet-related diseases have shifted from nutrient deficiencies to chronic diseases related to dietary excesses. This shift has led to increasing scientific consensus that eating more plant foods but fewer animal foods would best promote health. This consensus is based on research relating dietary factors to chronic disease risks, and to observations of exceptionally low chronic disease rates among people consuming vegetarian.

Current issues that need to be resolved include 1) the definition of an optimal vegetarian diet, not only in the context of human health but also in an ecological context meeting the nutritional needs of all groups of vegetarians;
2) cultivating an increased intake of a variety of plant based foods and establishing the number of servings and frequency, for disease prevention; 3 ) design of improved educational programs promoting the consumption of vegetables and fruit by giving more specific directions (Williams, 1995); 4) study the domain of phytochemicals sufficiently to identify their essential role in disease prevention, functional benefits and establish a recommended intake levels for humans; and 5) address the inadequate supply of vegetables and fruit with greater nutritional quality.

While the health claims associated with a wide range of phytochemicals and nutraceuticals are still tenuous and often described as needing more evidence, more research is needed in establishing specific roles of these individual nutraceuticals and establishing a required daily dosage for human beings. One is reminded of the 1920s, when vitamins were discovered. Although scientists knew that the vitamins were necessary for good general health and vision, they did not know the specific role of vitamins in good health nor what quantity was needed for effective protection of health and prevention of diseases. This is the case now with phytochemicals. With more focused and extensive research including human clinical trials the specific role of the individual phytochemicals and the mechanism of action may be identified to establish a daily dosage for daily intake.

Recognizing their importance, fruit and vegetables have been given a central position in the food pyramid, constituting the second in quantity after grains as well as frequency of intake. Current agricultural production of dietary components identified in the food pyramid is in substantial surplus for all groups except the vegetable and fruit group (Duxbury and Welch, 1999). According to the USDA dietary guidelines, the deficit in vegetable production is about $30 \%$ of current production (Duxbury and Welch, 1999). If all Americans consumed the recommended amount of fruit and vegetables as per the ADA guidelines, the supply of fruit and vegetables appear to be inadequate to meet the needs of all Americans, and if one considered the average per capita income of an American, the prices are also higher than what an average American can afford to spend (Kinsey and Bowland, 1999).

It is important that horticulture respond to the human nutrition requirements and increase the fruit and vegetable production by 1 ) increasing the area of production; 2 ) identifying or developing high yielding varieties; 3 ) exploring ways to reduce the prices of vegetables and fruit; 4) diversifying the production of vegetables by growing newer crops that have found their way in to the American diets due to a number of reasons (Palaniswamy, 2001); 5) develop suitable production strategies for the newly emerging food crops (Palaniswamy and Palaniswamy, 2001); 6 ) develop programs for promoting and marketing new crops and products, suggesting methods of preparation and consumption (Miles and Allman, 2001); 7) design crop improvement programs that include the nutritional requirement as a guiding note and improve the nutraceutical and functional properties of vegetables and fruit; 8) crop improvement by genetic modifications; 9) characterizing the environmental conditions and cultivation practices that would selectively manipulate and maximize the phytochemical concentrations in the produce (Palaniswamy et al., 2000a, 2000b, 2001a, 2001b, Rosenfeld et al., 1997); 10) achieve regional self-sufficiency by encouraging local production of vegetables and fruit; and 11) encourage organic crop cultivation to increase quality and a higher content of nutritionally significant minerals, vitamin $\mathrm{C}$, iron, magnesium, and phosphorus and lower amounts of nitrates and some heavy metals (Worthington, 2001); and 12) design of appropriate nutritional information and educational programs to increase healthful choices.

\section{Literature cited}

Abrams, Jr., H.L. 2001. Vegetarianism: Another view, p. 1564-1571. In: K.F. Kiple and K.C. Ornelas (eds.). The Cambridge world history of food. Cambridge Univ. Press, Cambridge, U.K.

Alcott, W.A. 1844. Vegetable diet defended. J. Chapman Publ., London.

American Dietetic Association. 1992. Pyramid power is here to stay: Behind the new food guide. J. Amer. Dietetic Assn. 92(8):925.

Anderson, J.J.B. 1999. Plant-based diets and bone health: Nutritional implications. Amer. J. Clinical Nutr. 70 (suppl):539S$542 S$.

Atkins, R.C. and S. Buff. 2000. Dr. Atkins' age-defying diet revolution. St. Martin's Press, New York. 
Ball, M.J. and M.A. Bartlett. 1999. Dietary intake and iron status of Australian vegetarian women. Amer. J. Clinical Nutr. 70:353358.

Bartsch, H. and N. Frank. 1996. Blocking the endogenous formation of $\mathrm{N}$-nitroso compounds and related carcinogens. Intl. Agency for Res. Cancer Sci. Publ. 139:189201

Bonci, L. 2001. Tackling the food guide pyramid.9Oct. 2001.<http://msnbc.com/news/ 622382.asp?cpl $=1>$.

Cheyne, G. 1813. An essay of health and long life. Edward Gillespy, New York.

Clarke, R., L. Daly, K. Robinson, E. Naughten, S. Cahalane, B. Fowler, and I. Graham. 1991. Hyperhomocysteinemia: An independent risk factor for vascular disease. New England J. Med. 24(17):1149-1155.

Corliss, R. 2002. Should we all be vegetarians? Time 160:48-56.

Craig, W.J. 1994. Iron status of vegetarians. Amer. J. Clinical Nutr. 59:1233S-1237S

Chinese Nutrition Society. 2000. Dietary guidelines and the food guide pagoda. J Amer. Dietetic Assn. 100:886-887.

Davis, C., P. Britten, and E.F. Myers. 2001. Past, present and future of the food guide pyramid. J. Amer. Dietetic Assn. 101:881885.

Duxbury, J.M. and R.M. Welch. 1999. Agriculture and dietary guidelines. Food Policy 24:197-209.

Dwyer, J.T. 1991. Nutritional consequences of vegetarianism. Annu. Rev. Nutr. 11:6191 .

Dwyer, J. 1999. Convergence of plant-rich and plant-only diets. Amer. J. Clinical Nutr. 70 (suppl):620S-622S.

Dyson, L.K. 2000. American cuisine in the 20th century. Food Rev. 23:2-7

Erhard, D. 1973. The new vegetarians. Part 1. Nutr. Today 8:4-12.

Franklin, T.L., K.M. Kolasa, K. Griffin, C. Mayo, and D.T. Badenhop. 1995. Adherence to very low fat diet by a group of cardiac rehabilitation patients in the rural southeastern United States. Arch. Family Med. 4:551554.

Freeland-Graves, J. 1988. Mineral adequacy of vegetarian diets. Amer. J. Clinical Nutr. 48:859-862.

Gould, K.L., D. Ornish, L. Scherwitz, S. Brown, R.P. Edens, M.J. Hess, N. Mullani, L. Bolomey, F. Dobbs, W.T. Armstrong, T. Merritt, T. Ports, S. Sparler, and J. Billings. 1995. Changes in myocardial perusion abnormalities by positron emission tomography after long-term intense risk factor modi- fication. J. Amer. Medical Assn. 274:894 901

Haddad, E.H., J. Sabaté, and C.G. Whitten. 1999. Vegetarian food guide pyramid: A conceptual framework. Amer. J. Clinical Nutr. 70(suppl):615S-619S.

Hankey C.R. and W.S. Leslie. 2001. Nutrition and coronary heart disease. Coronary Health Care 5:194-201.

Hänninen, O., K. Kaartinen, A.L. Rauma, M. Nenonen, R. Törrönen, S. Häkkinen, H. Adlercreutz, and J. Laakso. 2000. Antioxidants in vegan diet and rheumatic disorders. Toxicology 155:45-53.

HarrisInteractive, 2002. Do you consider yourself a vegetarian? Time/CNN Poll (59 Apr. 2002). Online interactive market research, Rochester, N.Y.

Kerr, G. 1974. Babies who eat no animal protein fail to grow at normal rate. J. Amer. Med. Assn. 228:675-676.

Key, T.H., M. Thorogood, P.M. Appleby, and M.L. Burr. 1996. Dietary habits and mortality in 11,000 vegetarian and health conscious people: Results of a 7-year follow up. Brit. Med. J. 313:775-779.

Key, T., N. Allen, E. Spencer, and R. Travis. 2002. The effect of diet on risk of cancer. Lancet 360:861-868.

Kinsey, J. and B. Bowland. 1999. How can the US food system deliver food products consistent with the dietary guidelines? Food marketing and retailing: an economists view. Food Policy 24:237-253.

Knutsen, S.F. 1994. Lifestyle and the use of health services. Amer. J. Clinical Nutr. 59(suppl):1171S-1175S.

Kushi, M and A. Kushi. 1992. Macrobiotic diet. Japan Publ., Briarcliff Manor, N.Y.

Kuresh, A.Y. and J.A. Joseph. 2001. A possible emerging role of phytochemicals in improving age-related neurological dysfunctions: a multiplicity of effects. Free Radical Biol. Med. 30:583-594.

Kwok, T., J. Woo, S. Ho, and A. Sham. 2000. Vegetarianism and ischemic heart disease in older Chinese women. J. Amer. College. Nutr. 19(5):622-627.

Lambe, W. 1815. Additional reports on the effects of a peculiar regimen. J. Mawman, London.

Lampe, J.W. 1999. Health effects of vegetables and fruit: assessing mechanisms of action in human experimental studies. Amer. J. Clinical Nutr. 70(suppl):475S-490S.

Leslie, M. and R.W. St Pierre. 1999. Osteoporosis: implications for risk reduction in the college setting. J. Amer. College Health 48:67-71.
Lin, C., T. Fang, and M. Gueng. 2001. Vascular dilatory functions of ovolactovegetarians compared with omnivores. Atherosclerosis 158:247-251.

Lyon, N. 1977. Cholesterol is just one heart threat. Sci. Dig. 81: 28-31.

McBride, J. 1998. Vegetarians can get enough zinc and other minerals from food alone.9 Oct. 2001. <http://www.ars.usda. gov/is/pr/1998/980325.htm>.

McIntyre, A., P.R. Gibson, and G.P. Young, 1993. Butyrate production from dietary fibre and protection against large bowel cancer in a rat model. Gut. 34:386-391.

Meirelles, C.M., G.V. da Veiga, and E.A. Soares. 2001. Nutritional status of vegetarian and omnivorous adolescent girls. Nutr. Res. 21:689-702.

Messina, M.J. 1999. Legumes and soybeans: Overview of their nutritional profiles and health effects. Amer. J. Clinical Nutr. 70 (suppl):439S-450S.

Messina V.K. and K.I. Burke. 1997. Position of the American Dietetic Association: Vegetarian diets. J. Amer. Dietetic Assn. 11:1317-1321.

Miles C.A. and D.G. Allman. 2001. Strategies for promoting and marketing Asian crops and products. HortTechnology 11(4):517-519.

Mitsuoka T. 1982. Recent trends in research on intestinal flora. Bifidobacteria and Microflora 1:3.

Navia, J.M. 1979. Nutrition, diet and oral health. Food Nutr. News 50:1-4.

Palaniswamy, U. 2001. Human dietetics and Asian food crops. HortTechnology 11(4):504-509.

Palaniswamy, U., R.J. McAvoy, and B. Bible. 2000a. Leaf yield and fatty acid composition of purslane (Portulaca oleracea L.) at different growth stages. J. Trop. Agr. (38):1-4.

Palaniswamy, U., R.J. McAvoy, and B. Bible. 2000b. Omega-3-fatty acid concentration in Portulaca oleracea L. is altered by nitrogen source in hydroponic solution. J. Amer. Soc. Hort. Sci. 125:190-194.

Palaniswamy K.M. and U.R. Palaniswamy. 2001. Production strategies for Asian horticultural crops. HortTechnology. 11:514516.

Palaniswamy, U., R.J. McAvoy, and B. Bible. 2001a. Omega-3- fatty acid concentration in Portulaca oleracea L. is altered by photosynthetic photon flux. J. Amer. Soc. Hort. Sci. 126:537-543.

Palaniswamy U.R., R.J. McAvoy, and B.B. Bible. 2001 b. Stage of harvest and polyunsaturated essential fatty acid concentrations in purslane (Portulaca oleraceae) leaves. J. 
Agr. Food Chem. 49:3490 -3493.

Phipps, W.R., M.C. Martini, J.W. Lampe, J.L. Slavin, and M.S. Kurzer, 1993. Effect of flax seed ingestion on the menstrual cycle. J. Clinical Endocrinol. Metab. 77:1215.

Plutarch, 1889. Of eating flesh, p. 3-16. vol. 5: In: W.W. Goodwin (ed.). Plutarch's miscellanies and essays, Little Brown, Boston, Mass.

Pronczuk, A., Y. Kipervarg, and K.C. Hayes. 1992. Vegetarians have higher plasma alpha-tocopherol relative to cholesterol than do non-vegetarians. J. Amer. College Nutr. $11: 50-55$.

Rajaram, S. and J. Sabaté. 2000. Health benefits of a vegetarian diet. Nutrition. 16:531-533 Rauma, A.L. and H. Mykkänen. 2000 . Antioxidant status in vegetarians versus omnivores. Nutrition 16(2):111-119.

Restaurants, USA. 1999. Vegetarian cuisine is in bloom on restaurant menus. 14 Oct. 2001. <http://www.restaurant.org/rusa/ 1999/january/9901p30.htm>.

Rosenfeld H.J., P. Baardseth, and G. Skrede. 1997. Evaluation of carrot varieties for production of deep fried carrot chips-IV. The influence of growing environment on carrot raw material. Food Res. Intel. 30:611-618.

Ryder, R. 1979. The struggle against speciesism, p. 3-14. In: D. Patterson and R. Ryder (eds.). Animals' rights-A symposium. Centaur Press Publ., Fontwell, U.K.

Sabaté, J., 2001. The public health risk-tobenefit ratio of vegetarian diets: Changing paradigms, p. 19-30. In: J. Sabaté (ed.). Vegetarian nutrition. CRC Press, Wash., D.C.

Sabaté, J., A. Duk, and C.L. Lee. 1999. Publication trends of vegetarian nutrition articles in biomedical literature, 1966-1995. Amer. J. Clinical Nutr. 70(suppl):601S607S.

Salmeron, J, J.E. Manson, M.J. Stampfer, G.A.Colditz, A.L. Wing, and W.C. Willett.1997. Dietary fiber, glycemic load, and risk of non-insulin-dependent diabetes mellitus in women. J. Amer. Med. Assn. 277:472-477.

Snowdon D.A. and R.L. Phillips, 1985. Does a vegetarian diet reduce the occurrence of diabetes? Amer. J. Public Health 75:507-512.
Spencer, C. 1995. The heretic's feast: A history of vegetarianism, Univ. Press New England, Hanover, N.H.

Steinmetz, K.A. and J.D. Potter. 1991. Vegetables, fruit and cancer. II. Mechanisms. Cancer Causes Control 1:427-442.

Taubes, G. 2001. The soft science of dietary fat. Science 291:2536-2545.

Tryon, T. 1683. The way to health, long life and happiness. E. Richardson, London.

Turner, J. 1980. Reckoning with the beast: animals, pain, and humanity in the victorian mind. Johns Hopkins Univ. Press, Baltimore, Md.

U.S. Department of Agriculture, 1943. Basic 7 food guide (1943-1955). 14 Oct. 2002. <http://www.nal.usda.gov/fnic/ history/basic7.htm>

U.S. Department of Agriculture, 1958. Basic 4 Food Guide (1956-1979). USDA, Agriculture Research Service, 14 Oct. 2002. <http://www.nal.usda.gov/fnic/history/ $7553 \mathrm{v}$.gif>

U.S. Department of Agriculture. 1989. Pattern for Daily Food Choices (1984-present). USDA, Human Nutrition Information Service, 14 Oct. 2002. <http://www.nal.usda. gov/fnic/history/pat.htm>

Vegetarian Times, 1992. The American vegetarian: Coming of age in the $90 \mathrm{~s}-\mathrm{A}$ study of the vegetarian market place conducted for Vegetarian Times by Yankelovich, Skelly and White/Clancy, Shulman, Inc., Glen Allen, Va.

Weinsier, R. 2000. Use of the term vegetarian. Amer. J. Clinical Nutr. 71:1211-1213.

Whorton J.C.2001. Vegetarianism,p. 15531563. In: K.F. Kiple and K.C. Ornelas (eds.). The Cambridge world history of food. Cambridge Univ. Press, Cambridge, U.K.

Williams, C. 1995. Healthy eating: clarifying advice about fruits and vegetables. British Med. J. 310:1453-1455.

Worthington, V. 2001. Nutritional quality of organic versus conventional fruits, vegetables, and grains. J. Alt. Complementary Med. 7:161-173. 